\title{
Empowering Volunteer Spirit through The King's Philosophy to Solve Problems in Community: A Case Study of Volunteer Spirit Group in Phutthamonthon, Nakhonchaisri, and Sam Phran District Nakhon Pathom* Province.
}

\author{
Somchai Saenphumi ${ }^{1}$, Worachet Tho-un ${ }^{2}$ \\ ${ }^{1}$ Mahamakut Buddhist University, ${ }^{2}$ Mahamakut Buddhist University \\ Email: ${ }^{1}$ Somchai.sa@mbu.ac.th, ${ }^{2}$ worachet.th@mbu.ac.th.
}

\begin{abstract}
This research article aims to study, analyze, and develop community capacity to empower communities and prevent social problems in Nakhonpathom province. This work is qualitative research and uses documentary research to create training prototypes and focus groups among sample groups or key informants. This is a group of volunteers' spirits, Phutthamonthon, Nakhonchaisri Samphran district totaling 34 people to be aware of the community's problems.

The study results showed that the training model obtained from the document's synthesis and processing consisted of the volunteer concept, The King's philosophy, the concept of community empowerment. After that, the focus groups found that the volunteer spirit group in the Phutthamonthon district voted that the garbage problem was the biggest, consistent with the volunteer spirit in Samphran district. Both groups propose a waste separation campaign, support equipment from government agencies, educators. In contrast, the Nakhonchaisri district volunteer spirit group resolved that the problem of invasion of the Tha-chin river was the most important. Moreover, proposed state legislation to create a group to negotiate seriously with the government and put pressure on those who transgress the river, including the media as a tool of pressure. Finally, by training the model with a volunteer group, they will understand the problems in their communities and formulate groups to solve problems in the community through volunteer activities.
\end{abstract}

Keywords

Empowering, Volunteers Spirit, The King's Philosophy, Community Potential

Article Received: 10 August 2020, Revised: 25 October 2020, Accepted: 18 November 2020

\section{Introduction}

Under the present Thai society context, it focuses on material prosperity according to capitalism, economic growth, and technological advancement. This causes Thai society to become highly competitive, leading to social inequality and social problems. Under such circumstances, it dramatically affects Thai people's way of life, such as having material values and pursuing personal interests more than the public. Doing for the public, which is a gap that causes many social problems such as drug addiction, community non-waste separation problem, river intrusion problem [1]

The public sector under the volunteer spirit group (Klumčhit' $\bar{a} s \bar{a}$ ) in Nakhon Pathom Province has begun to play a more significant role in organizing social activities. In particular, the volunteer spirit group in Phuthamonthon District has about 2,500 members, the Nakhon Chai Si district volunteer spirit group has approximately 2,000 members, and the Sam Phran district volunteer spirit group has approximately 1,800 members. It is an essential group of people who can add skills to organize activities to empower the community and the community's problems. The researchers are interested in studying to empower the community by building community empowerment tools by creating a volunteer model to develop community potential through volunteer networks in the area. The researchers will apply the concept of community empowerment and volunteerism to strengthen co-operation with the community through the King's philosophy of understanding, connecting, and developing in line with the government policy and the 20-year national strategy in the fourth issue on security. Section 4.2 emphasizes the application of The King's philosophy. Along with the introduction of Dhamma for unity, which means unity, unity, satisfaction with one another. To develop community co-operation to strengthen the community to have co-operation to prevent such problems sustainably. This will benefit the most people in Nakhon Pathom and can use this format to be disseminated for development and application in other areas.

\section{Objective}

Analyze, and develop community capacity to empower communities and prevent social problems in Nakhonpathom province.

\section{Methods}

This study is qualitative research, finding data from documentary research, and collecting data through a focus group. Key informants from using purposive sampling to depth information. The researchers have identified the people involved in the volunteer spirit activities and conduct them regularly. The volunteer spirit groups are included in each district as follows: volunteer spirit, Phutthamonthon District 15 people, Nakhon Chai Si District 10 people, Sam Phran District 9 people, total of 34 people. 


\section{Concepts for training volunteer spirit groups.}

Community empowerment. Many scholars have focused on "Community empowerment," such as the work of Paulo Freire[2] describes community empowerment as the process by which people in the community or villagers are involved. (Which is held in a state of silence and despair) gathered through dialogue and praxis to form a "consciousness." Formed the foundation of change for the release of bondage to meaningful and well-being. Better than before. While Saul D. Alinsky [3] viewed that the process by which the have-nots realized mutual benefits resulted in the exchange of knowledge through the establishment of the positive power of empowerment. Movements and changes aimed at restoring the dignity and dignity of humanity, justice, and resource distribution. In addition, Glenn Laverack [4, p. 20] mentions the rendering of community energy as a process by which communities create something of value and character that gives them the power to shape their destiny and give them the power to shape their lives. It has a precise aim to change society and politics by driving changes in public policy, making decisions of the state, and distributing resources. On the other hand, Jim Ife [5, pp. 67-68] sees it as a process of the disadvantaged to challenge or change the central discourse to lead the struggle for liberation, growth, and freedom from disadvantaged experiences. This concept is not a form of "Power-over," but rather a concept of "Power to" and "Power-with."[6]

Tools for community empowerment. The idea that the community's power from these scholars on the above, the investigators have chosen to bring the tool to empower communities of Paulo Freire used as his study of the oppressed and to establish the power of the people. Oppressed, which in the present context is the countryside itself. Freire explains that the problem of suppression comes from a silent culture and bank education. It creates a state of helplessness of the oppressed arising from the condition of humiliation and dehumanization. With oppressors taking away the poor's humanity, these people did not dare to retaliate because the state of "Fear of freedom" was always comparable. These birds do not have to go for their food but will be brought by someone. The wings are weak because they have not been used for a long time. When released from the cage, Scared of danger, these birds did not fly away and returned to their cages. Fear of confrontation with wild birds and fear of feeding themselves, so they are afraid to live independently. [2, p. 67]

Freire describes the "powerlessness" of the villagers in "silent culture" because the voices of the countryside are usually not heard due to two reasons: 1) To be labeled uneducated and foolish by society. Therefore, society does not need to value useless villagers. 2) The rural villagers themselves view themselves as worthless. Because it is in a humble culture that causes them to lose confidence in themselves, they do not dare to stand on their legs in the meantime instead preferred the dependence of others. As a result, it has been repeatedly produced through family systems and bank education, which destroy the community's thinking, analysis, and voting. Also, cultural aggression worsened the villagers' lack of belief in themselves. Under such conditions, the empowerment process could not take place. To empower the community, Freire sees the need to dissolve the "silence culture" first. To provide villagers opportunities to think, analyze, and speak through Informal small-scale dialogue or "cultural groups" activities. To provide a platform for community members to exchange ideas fully. This activity will be an important factor in creating creativity. It also resulted in the villagers to gain more confidence and raise their "conscience" level. [2, pp. 38-39]

The King's philosophy is a science that arises following the principles of work, understanding, Connecting, and developing King Rama IX that he applies to people, material, society, environment, and culture. The tool has been used in many royal projects that comprise a variety of ideas. [7, pp. 543-546] The researchers chose the volunteer spirit group's appropriate principles, the "Understanding, Connecting, and Developing" work principles. [8, p. 205]

Understanding is understanding problems that exist. Whether it is understood through personal experience and research and being prudent and careful in obtaining accurate information can lead to a correction. The use of empirical data is the understanding of various statistical data. For example, population, number of households, analytics, and research can draw academic or government agencies to join research with the community or volunteer spirit group to bring academic principles to understand problems and propose development or solution solutions. Experiment till actionable results are to do it repeatedly and take the lessons down and build a model.

Connecting is inside-out blasting. People or groups of volunteer spirit must have the intention to develop themselves first. They are not waiting for the development of government policy only. Understand target is the needs of the community that they want to solve any problems. If the problem is too big, the volunteer spirit group Can reflect the problem to anyone or any agency as for the problems that can be achieved, solutions Because the volunteer spirit group is the individual or target group, Educate the use of easy-to-understand language to communicate with the volunteer spirit people or group. To create understanding and awareness of problems that must be resolved together.

Development must start with Self-initiated a volunteer spirit group must not coerce others to join the development concept must be self-imposed. He suggested, in the story of the inner explosion, Self-reliance emphasizes self-action. Prototype and role model brings knowledge to build a reliable model for dissemination to the community, or other volunteer spirit groups can be applied. Use by doing this, and people will learn from the prototype and be an excellent inspiration for the development of the people and the nation. Volunteer's concept is the spirit of giving willingly, not expecting compensation, sacrificing time for others and society, focusing on development, including emotional and social support, such as providing love, care, tooling, material support, and information.

Public consciousness refers to a ready person's psychological traits, the desire to help solve problems and devote themselves to the common good. Including the use and treatment of shared objects, there are many levels from the family, community, and society levels.

Public consciousness $=$ Public mind is an essential component of civil society, which is part of the civil society 
theory. So, the volunteer spirit concept is in three principles; [9, pp. 3-5]

1.) Helping others is to use services to solve problems, share items without expecting anything in return.

2) Sacrifice for society is the sacrifice of one's own time for others willingly.

3) Development focus is to pay attention to changes or problems that occur in society, communities, ideas for the development of society, communities, and organizations. As well as develop activities promoting volunteer spirit to develop a creative and diverse community society appropriately [10]

\section{Results}

After processing the documents, the researchers created a body of knowledge to train the representatives of the three groups of volunteer spirit groups, namely, The King's philosophy, the principles of understanding, connecting, and developing, the volunteer spirit concept and empowering the community. Especially the silent culture dissolution to enhance skills and knowledge for the three groups of volunteer spirit groups after the training, the researchers performed three steps as follows:

\section{After the training.}

From the observation, most of the volunteer spirits knew only the Sufficiency Economy Philosophy. Only a handful of people have studied The King's philosophy; most others lack the confidence to answer a questionnaire. It may be because they worry that the answer to them is wrong from others. Later, it was found that after the volunteer spirit group training in Nakhon Chaisri District, it will bring knowledge to practice such as being a good example, bringing knowledge to expand results and applying, inviting members to become a volunteer spirit voluntarily. In conjunction with the volunteer spirit group, Phutthamonthon District, such as inviting others to join to understand The King's philosophy, to build unity in the community through essential days, use guidance and step-by-step approaches, including help the people in need.

While the volunteer spirit group, Sam Phran District, suggested that they could develop community potential when trained by creating learning to realize by clarifying when there was community meeting among the elderly, senior school, grouping in the community for good deeds. Subsequently, it was found that the main principles understood Connecting and developing to solve problems in the community, the volunteer spirit group, Sam Phran District provides information that it is understood, that is, understand the condition of the community, with precise information. Villages visited to ask about problems such as the disabled, the vulnerable, bedridden, and the elderly, with a team of volunteer spirit visiting. To develop, there is training at various learning centers. Simultaneously, the volunteer spirit group in Nakhon Chai Si District gave the information that Understands the problems that arise in each community. Connecting by sincere help, with unconditional love, develop him not to change his way of thinking So life will change.
Finally, the volunteer spirit group in Phutthamonthon District gave information that the principle of understanding is to apply the principles of understanding that already exist in the community and apply them and what the community needs and foster intelligence for children and women.

\section{Discussing problems in the community.}

After the first part of the training and discussion, the researchers conducted a second-semester discussion or discussion to allow the three volunteer spirits to apply the concept of community empowerment that they had just trained. The dissolution of "silent culture" that everyone has to say and address issues, big or small. Participants are then asked to vote on a critical issue for the community and the volunteer spirit group, which can be used to create their own dialogue activities and design activities to prevent or mitigate them. In this section, the results of the study are as follows: volunteer spirit group, Phutthamonthon district, presents problems such as garbage, drugs, air pollution, consciousness, dengue fever. Next, the volunteer spirit group, Nakhon Chai Si District, present their problems at the meeting, such as the Tha Chin River's invasion, different ideas, game addicted youth, and lack of harmony. Finally, the volunteer spirit in Sam Phran district presented their problems at the meeting, such as garbage problems, family problems, income problems of disabled people. Regarding aid, the three groups wanted to make the community more conscious, including helping with various resources from government agencies.

\section{Voting is an important issue and can be created as an activity as a volunteer spirit.}

In the final phase, the researchers organized a forum for all panelists to present their problems during the second phase to exchange and raise support from the other participants. The vote results showed that the volunteer spirit group, Phutthamonthon District, the majority voted "garbage problem" as an urgent and essential problem and able to create activities under the volunteer spirit group to solve the problem. Subsequently, the majority of volunteer spirit, Sam Phran District, voted on the "garbage problem," which was consistent with the Phutthamonthon District problem. Because these two districts are connected and have a metropolitan condition adjacent to Bangkok, finally, the volunteer spirit group, Nakhon Chai Si District the majority of voters voted for "The Tha Chin River invasion problem is an urgent issue and can create activities under the volunteer spirit group to solve the problem. 


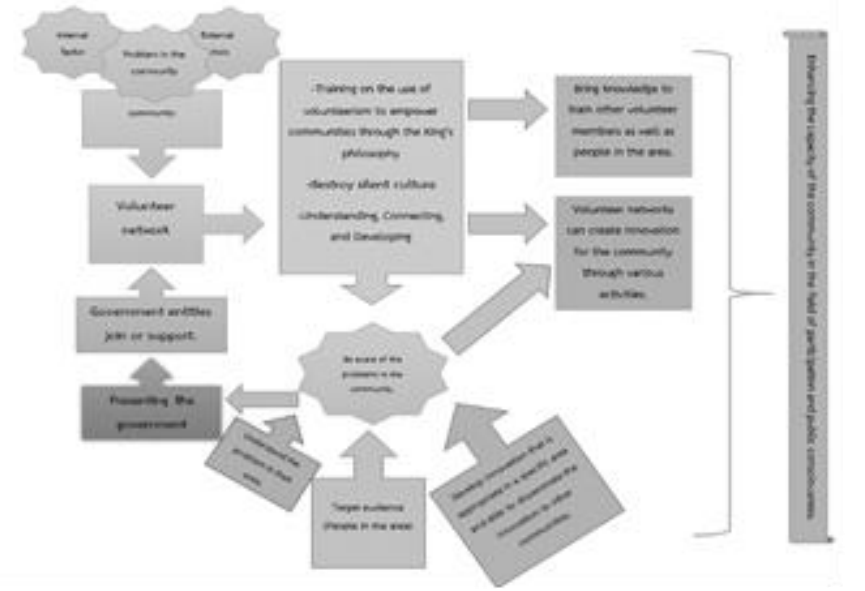

Figure 1: Model of Volunteering for Community Empowerment with the King's Philosophy.

\section{Discussions}

Research studies have shown that empowering communities through training to dissolve silent culture can increase the community's potential in participation because everyone can identify the problem and work together to seek solutions. This includes a case study on the community's role in forest fire co-operation of Arifudin, et al. [11, p. 131], explains that strengthening communities to empower them to participate in sustainable rural development. The indicators are empowerment and motivation for them to solve problems and make independent decisions. Make it competent, have the skills to plan and implement environmentally friendly practices. It is consistent with Brinkerhoff \& Azfar [12, pp. 5-6] that members of the community work together to increase influence, increase control, and jointly decide on issues that directly affect them. Under which members have sufficient mutual benefits that they can create incentives for them to act together. Also, the implementation of the principle of understanding, connecting, and developing to analyze the community's problems also corresponds to the explanation of the driving committee of The King's philosophy that studies the concepts of King Rama IX [8, p. 205]. Therefore, the results of research, training, and dialogue are valuable to apply to other communities. To drive and disseminate knowledge of The King's philosophy to develop community potential to be sustainable.

\section{Conclusion}

From the training and data collection, it was found that the volunteer spirit group will use the knowledge gained to develop community potential around participation and public mind such as building unity on important days, inviting people to join the network to solve problems in the community jointly. Connecting target groups or asking vulnerable people and developing a training facility or learning center in various fields and to jointly monitor the community. Finally, understand the problems that arise in each community, connecting with sincere help, unconditional love, and developing them not to change the way they think life will change. All of this demonstrated that the volunteer spirits were aware of their problems and needed to apply the knowledge from the training to problem analysis, especially problem understanding, connecting target groups, and developing solutions.

Besides, during the community dialogue, the researchers found that volunteer spirit members could independently reflect the problems they encountered and practiced the individual members' silent culture dissolution. The researchers voted to decide which is the most important and which volunteer spirits can design activities to address. The resolution results found that the volunteer spirit group in Phutthamonthon District and Sampran District had the same opinion and resolution as "The problem of garbage in the community." The volunteer spirit group in Nakhon Chaisri District voted that private encroachment on the Tha Chin River was the most critical problem. From such a problem that the researchers can create a process of creating a circuit or a model "using volunteer spirit to empower the community with The King's philosophy." To be an innovation for the volunteer spirit group in Nakhon Pathom and other provinces by applying the model accordingly.

Regarding the garbage problem, the researchers propose a solution by campaigning and using the $3 \mathrm{R}$ waste separation concept model and creating a recycling bank. To allow the volunteer spirits of both areas to continue to organize waste reduction campaigns through the model. The problem of encroaching on the Tha Chin River will use a form of integration to pressure government agencies and use the media, social media, as a channel for disseminating news and problems.

Finally, this research has also found that bringing the existing volunteer spirit groups in the existing areas to training and increasing their skills to become the volunteer spirit network empowers the community with The King's philosophy. They can perform activities better than other groups because the volunteer spirit is familiar with government agencies. Especially in the district and local government organizations, this familiarity comes from participating in activities with each other, whether it be important days, activities for receiving royal hats and scarves, etc. The researchers found that the volunteer spirit group is a group of people with strength in social capital. When organizing community empowerment activities or to resolve community problems in the future, it may be wellcoordinated with government agencies, and the activities will be easier to achieve than those organized by other groups.

\section{References}

[1] The Narcotics Control Board, "Strategic Plan for the power to overcome addiction 2012," The Narcotics Control Board, 2012.

[2] P. Freire, Pedagogy of the Oppressed, Middlesex: Penguin Books, 1986.

[3] S. D. Alinsky, Ruler for Radicals: A Pratical Primer for Realist Radicals, New York: A division of Random House Inc, 1989. 
[4] G. Laverack, Health Promotion Pratice: Buildig Empower Communities, Berkshire: Open University Press, 2007.

[5] J. Ife, Community Development in an Uncertain World: Vision, Analysis and Practice, Melbourne: Cambridge University Press, 2015.

[6] S. Samukkethum, Community empowerment and sustainable development, Bangkok: Faculty of Social and Environmental Development National Institute of Development Administration, n.d..

[7] B. Watthanabut, ".The King's Philosophy and Thai People development," The Journal of MCU Peace Studies, vol. 6, no. SP, p. $539-552,2018$.

[8] Steering Committee The King's Philosophy, "Driving the King's philosophy to reform the country," The Secretariat of the House of Representatives, Bangkok, 2017.

[9] S. Hunpayon, "Volunteer work in Thailand and its future direction," Journal of the Volunteer Graduate School, vol. 9, no. 2, pp. 1-39, 2013.

[10] N. Siboriboon, "Development of a causal model of students' volunteer mind in the upper secondary schools under the Office of the Basic Education Commission," 2007.

[11] Arifudin, B. Nasrul and Maswadi, "Program of Community Empowerment Prevents Forest Fires in Indonesian Peat Land," Procedia Environmental Sciences, vol. 17, pp. 129-134, 2013.

[12] D. W. Brinkerhoff and O. Azfar, "Decentralization and community empowerment: does community empowerment deepen democracy and improve service delivery?," United States agency for international development (USAID), Washington DC., 2006. 